Article

\title{
Relevance of Rheology on the Properties of PP/MWCNT Nanocomposites Elaborated with Different Irradiation/Mixing Protocols
}

\author{
Mercedes Fernandez ${ }^{1, *(D)}$, Arrate Huegun ${ }^{2}$ and Antxon Santamaria ${ }^{1}$ \\ 1 Polymer Science and Technology Department and Polymer Institute POLYMAT, \\ University of the Basque Country (UPV/EHU), Joxe Mari Korta Building, Av. Tolosa 72, \\ 20018 Donostia-San Sebastian, Spain; antxon.santamaria@ehu.eus \\ 2 CIDETEC Research Center, Polymers and Composites, Po Miramón 191, \\ 20014 Donostia-San Sebastian, Spain; ahuegun@cidetec.es \\ * Correspondence: mercedes.fernandez@ehu.eus; Tel.: +34-943-018-185
}

Received: 3 December 2018; Accepted: 4 January 2019; Published: 9 January 2019

\begin{abstract}
Linear and nonlinear rheological features and electrical conductivity of two nanocomposite systems based on polypropylene/multiwall carbon nanotubes (PP/MWCNT) are investigated. The nanocomposites were irradiated with an electron beam following two different procedures. Protocol A, where the nanocomposite mixture is irradiated, and Protocol B where only the PP matrix is irradiated before mixing with MWCNT. The same irradiation dose adjusted to bring about long chain branching (LCB) but not crosslinking, is used in both types of nanocomposites. The modification of the polymer matrix viscosity caused by irradiation determines the MWCNT dispersion and therefore the rheological and percolation thresholds. Elongational flow results reveal that strain hardening, typical of irradiated PPs, is observed for the nanocomposites irradiated, but not for the nanocomposites prepared with the irradiated PP. The hypothesis of a shear flow modification that aligns the branches into the backbone, eliminating the strain hardening is considered.
\end{abstract}

Keywords: nanocomposites; LCB polypropylene; rheology; oscillatory flows; elongational flow

\section{Introduction}

One of the advantages of long chain branched PP is that it can be processed using techniques, like extrusion-blowing, blow molding, foaming extrusion and thermoforming, not affordable for linear PP. It is known that these industrial processing methods require the polymer melt showing a strain-hardening behavior in elongational flow, i.e., a rapid increase of the uniaxial extensional viscosity beyond a critical strain.

The inclusion of long chain branches (LCB) in a PP structure can be done by three different methods: Radical chemical modification, radical grafting with different monomers (for instance styrene and vinylsiloxane) and using electron-beam irradiation (EB) [1].

The modification of the molecular structure of linear isotactic polypropylene (PP) by electron-beam irradiation has been a subject of interest during the last few decades [1-8]. Adequate doses of irradiation lead to LCB, and chain scission (molecular weight reduction), still avoiding crosslinking. The primary effect of irradiation on thermoplastic polymers is to produce free radicals after the scission of bonds. These built radicals lead to further changes in molecular structure through chemical reactions. The main molecular effects are chain scission, chain branching, and crosslinking. Usually, all these reactions are in competition and take place simultaneously. Which reaction predominates depends on chemical structure and morphology of the polymer, as well as on the irradiation conditions (applied dose, dose rate and type of radiation) and annealing time and temperature. The specific 
conditions that favour the formation of LCB in polypropylene by EB irradiation and without additives, were determined by Rätzsch et al. [1]. According to these authors, the material should be irradiated under inert atmosphere and at a temperature below $100{ }^{\circ} \mathrm{C}$, i.e., in solid state. Subsequent to the irradiation process, the polypropylene should be submitted to a thermal treatment for two reasons: First, the life time of macro-radicals is prolonged in order to raise the possibilities for branching, and second, the residual macro-radicals can be eliminated.

Very few papers refer to the effect of irradiation on polymer nanocomposites [9-14]. With the aim of improving the range of industrial applications, we have recently irradiated PP/MWCNT (Multiwall Carbon Nanotubes) nanocomposites, obtaining an electrical conductive polypropylene with strain-hardening behavior [12,14]. To our knowledge, elaboration of PP/MWCNT nanocomposites using irradiated PPs as a polymer matrix has not been reported in the literature, so far. The type, length, density and distribution of branches are known to dramatically affect polymer flow behavior and processing characteristics. Understanding the role of LCB in relation to the properties of these materials is of great academic and industrial interest, but, in general, the effect of the molecular architecture of the matrix has deserved little attention on the characterization of polymer nanocomposites. Espinoza-González et al. [15] reported that a patented method of extrusion assisted by a low-frequency and high-power ultrasound method was able to induce different states of dispersion, as well as chemical modifications promoted by branching reactions. The presence of branched structures affects the quality of the dispersion of CNTs. Vega et al. [16] demonstrated that high molecular weights or considerable molecular weight polydispersities can play a determining role in melt viscoelastic properties of polyethylene/carbon nanotube nanocomposites, which have important implications on determining rheological percolation thresholds, due to the viscoelastic screening effect of the CNTs.

The characterization of the structural modification produced by the electron-beam irradiation process in PP/MWCNT nanocomposites is a challenging task. Size Exclusion Chromatography (SEC) combined with MALLS (Multi-Angle Light Scattering) is a very suitable tool to ascertain the sparse long chain branching level in polyolefins [17]. However, this technique cannot be employed in the case of polymer nanocomposites, because proper solutions to be injected in SEC equipment cannot be prepared. Therefore, rheological methods are used to face this issue. Our research focuses on the influence of both, carbon nanotubes and the irradiation process on the rheological and electrical properties. The rheological characterization of nanocomposites is based on the study of the dynamic viscoelasticity and uniaxial elongational flow.

Two PP/MWCNT nanocomposites are compared: One is a PP/MWCNT nanocomposite that has been submitted to irradiation (Protocol A); the other is a PP/MWCNT nanocomposite obtained by mixing MWCNT with an irradiated PP (Protocol B). The same irradiation dose, adjusted to bring about LCB, but not crosslinking, was used in both types of nanocomposites. Furthermore, the mixing conditions (temperature, mixing time and applying torque) were the same in both elaboration protocols. The paper is organized focusing on the following issues: (a) Similarity and differences found between both nanocomposites; (b) effect of irradiation on polymer matrix viscosity and, subsequently, influence on MWCNT dispersion; (c) influence of long chain branching developed by irradiation: strain hardening in elongational flow; (d) capacity of the mixing process to annihilate LCB and, alternatively, to promote shear modification (alignment of long branches to the backbone); (e) explaining why only one of the nanocomposites displays strain hardening.

\section{Materials and Methods}

The basic material used in this study was a commercial isotactic polypropylene Moplen EP340K $\left(\mathrm{M}_{\mathrm{W}}=440,000, \mathrm{M}_{\mathrm{W}} / \mathrm{M}_{\mathrm{n}}=4.4\right)$ provided by Basell polyolefins company (London, UK). We refer to this polymer as "neat PP". Non-functionalized Multiwall Carbon Nanotubes (MWCNT) supplied by Cheap Tubes Inc (Cambridgeport, VT, USA) were selected to be dispersed in neat PP matrix. These nanotubes have specified diameters of $\mathrm{D}=30-50 \mathrm{~nm}$, lengths of $\mathrm{L}=10-20 \mu \mathrm{m}$ and purity greater than $95 \%$. 
Before the melt-mixing process, polymer powder was prepared from pellets using a Mill Retsch ${ }^{\circledR}$ ZM 200 (Haan, Germany) and both polymer powder and MWCNT were properly dried. PP was dried at $\mathrm{T}=80^{\circ} \mathrm{C}$ in a vacuum oven during $2 \mathrm{~h}$ and MWCNT were dried at $\mathrm{T}=100{ }^{\circ} \mathrm{C}$ during $2 \mathrm{~h}$. The polymer and MWCNT were stirred to obtain a homogeneous mixture. A blend of Irganox 1010 and Irgafos 168 (BASF, Basel, Switzerland) was added to prevent the degradation of the irradiated polypropylene. The powder mixture was blended in a Haake Mini-Lab twin-screw extruder (Thermo Electron Coorp., Hamburg, Germany). The mixing was processed for $10 \mathrm{~min}$ at $\mathrm{T}=180^{\circ} \mathrm{C}$ and $100 \mathrm{rpm}$ using a counter-rotating screw configuration.

Irradiated pure PP and MWCNT/PP nanocomposites were obtained by electron-beam irradiation. The process was performed under inert atmosphere at room temperature with an EB by IONMED (Cuenca, Spain). The acceleration energy was $10 \mathrm{MeV}$ and the irradiation doses were 20, 50 and $80 \mathrm{kGy}$. After irradiation, samples were heated to react with the residual radicals.

The nanocomposites were prepared following two different protocols. Protocol A consisted of irradiating the prepared nanocomposites, whereas in protocol B neat PP powder was irradiated before the mixing process and, after, nanocomposites were prepared using irradiated neat $\mathrm{PP}$ as the matrix. To facilitate the comprehension to the reader, the specimens were named with the following sequential nomenclature: Protocol A: PP/MWCNT, load and irradiation dose and Protocol B: PP, irradiation dose/MWCNT, load.

The mixtures were compression molded using a hydraulic press at $180^{\circ} \mathrm{C}$ for $5 \mathrm{~min}$; the last $2 \mathrm{~min}$ at a maximum pressure of 100 bars. Then, the sheets were allowed to cool at room temperature outside the press. The thickness of the sheets was adjusted depending on the experiment.

The dynamic viscoelastic functions, storage or elastic modulus, $G^{\prime}$, loss or viscous modulus, $\mathrm{G}^{\prime \prime}$ and complex viscosity, $\eta^{*}$, were determined in an ARG2 (TA Instrument, New Castle, DE, USA) rheometer with parallel-plate fixture ( $25 \mathrm{~mm}$ diameter). Dynamic frequency sweep experiments were carried out in a frequency range of $0.0628-628 \mathrm{rad} / \mathrm{s}$ at a temperature of $\mathrm{T}=190{ }^{\circ} \mathrm{C}$. Actually, small amplitude oscillatory shear (SAOS) measurements were carried out, ensuring that the strain amplitude was within the linear viscoelastic range. For the analysis of the non-linear viscoelasticity, large amplitude oscillatory shear (LAOS) measurements were performed using an ARES rheometer (Rheometric Scientific) to study the effect of the strain amplitude on $G^{\prime}$ and $G^{\prime \prime}$ at a constant frequency of $6.28 \mathrm{rad} / \mathrm{s}$. Parallel plates of $12 \mathrm{~mm}$ diameter were employed. For data acquisition a 16-bit ADC card was used (National Instruments, Austin, TX, USA) and Fourier Transformation analysis was carried out employing LabView Software Program developed and kindly supplied by Prof. M. Wilhelm [18].

Extensional measurements were performed at a temperature of $\mathrm{T}=180^{\circ} \mathrm{C}$ using the Extensional Viscosity Fixture (EVF) of the ARES rheometer. The extensional viscosity was determined as a function of time at different extensional rates ranging from 0.01 to $1 \mathrm{~s}^{-1}$.

Molecular parameters of non-irradiated and irradiated polypropylene were evaluated using high temperature size exclusion chromatography (SEC) coupled with an infrared detector (IR) as the primary detector and multiangle laser light scattering (MALLS). This was completed with an on-line viscometer (VI) to determine the intrinsic viscosity, which allowed for evaluation of the LCB degree. The solvent was trichlorobenzene (TCB) stabilized with $300 \mathrm{ppm}$ butylated hydroxytoluene (BHT). Mass recovery was always higher than $95 \%$, and not a single impediment was found to dissolve all the samples, which leads us to assume that irradiation did not cause crosslinking. Data were acquired and processed by Polymer Char Company (Valencia, Spain) following the procedure described elsewhere [12].

Electrical conductivity was measured at room temperature by means of the ARES Rheometer Dielectric Analysis option (DETA) with an Agilent E4980A Bridge. Dielectric data $\left(\varepsilon^{\prime \prime}\right)$ were recorded for each sample as a function of frequency, and the conductivity was calculated using the equation:

$$
\begin{gathered}
\sigma \prime(v)=\varepsilon_{0} 2 \pi v \varepsilon^{\prime \prime}(v) \\
\varepsilon_{0}=8.85 \times 10^{-12} \mathrm{~F} \cdot \mathrm{m}^{-1}
\end{gathered}
$$


Transmission Electron Microscopy (TEM) images were obtained to study the dispersion state of the nanocomposites. Nanocomposites were trimmed using an ultramicrotome device at $\mathrm{T}=-60{ }^{\circ} \mathrm{C}$ (Leica EMFC6; Leica Microsystems, Vienna, Austria) equipped with a diamond knife. The ultrathin sections $(100 \mathrm{~nm})$ were placed on 300 mesh copper grids. The surfaces were observed by TEM (TECNAI G2 20 TWIN; FEI Company, Eindhoven, THe Netherlands), operating at an accelerating voltage of $200 \mathrm{KeV}$ in a bright-field image mode. TEM results display a two dimensional cut of a 3D structure and, therefore, it is not possible to see through going pathways formed by agglomerates.

\section{Results}

\subsection{Small Amplitude Oscillatory Shear (SAOS) Flow, Electrical Conductivity and TEM Results}

The elastic or storage modulus $\mathrm{G}^{\prime}$ as a function of frequency for the nanocomposites prepared, respectively, using Protocols A and B are presented in Figure 1a.

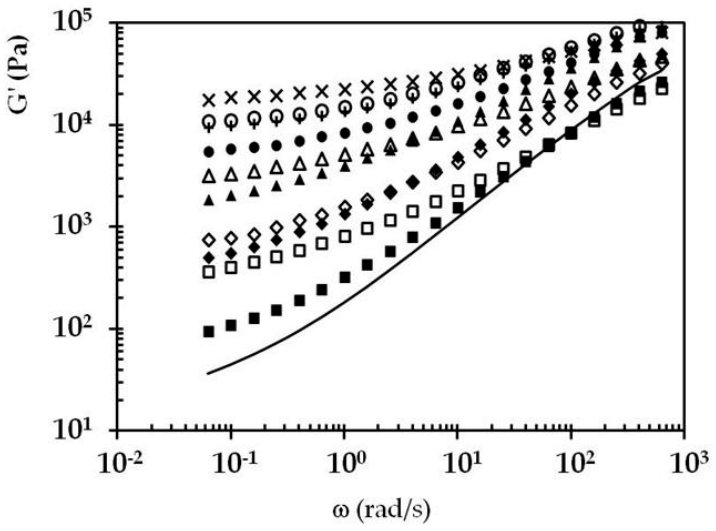

(a)

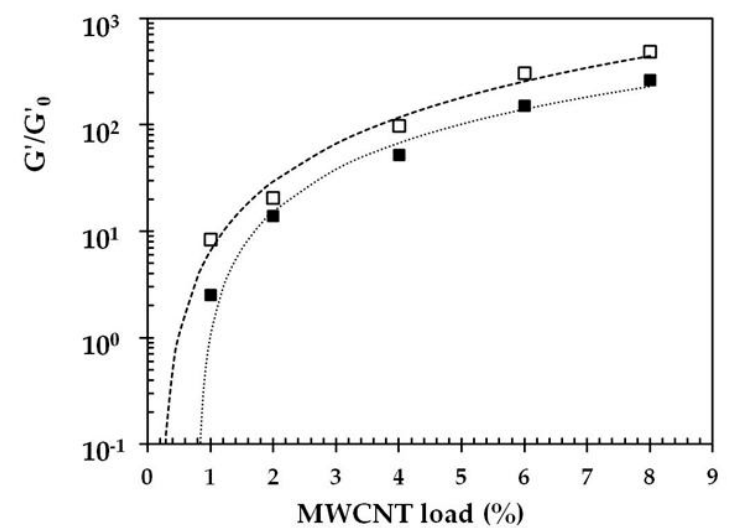

(b)

Figure 1. (a) Storage modulus as a function of frequency for both nanocomposites. Line corresponds to unloaded irradiated PP 80Kgy. Protocol A (filled symbols), PP/MWCNT $80 \mathrm{kGy:} \mathrm{( \square )} \mathrm{1 \% ,} \mathrm{( \diamond )} \mathrm{2 \% ,}$

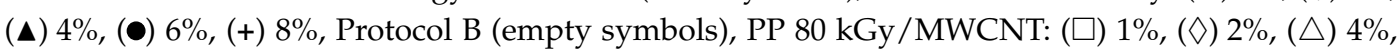
(○) $6 \%,(\times) 8 \%$; (b) percolation plot: $\mathrm{G}^{\prime} / \mathrm{G}^{\prime}{ }_{0}$ versus MWCNT load for both nanocomposites. The values of the moduli are taken at a frequency of $0.0628 \mathrm{rad} / \mathrm{s}$ and $\mathrm{G}^{\prime}{ }_{0}$ refers to the storage modulus of unloaded irradiated PP.

The results show that the elastic modulus tended to level off as the nanotube's concentration increased, giving a scale law $\mathrm{G} \sim \omega^{\mathrm{n}}$ with $\mathrm{n}$ values close to 0.5 . Moreover, at these concentrations the elastic modulus overcame the viscous modulus, $G^{\prime}>G^{\prime \prime}$ (not shown to avoid data overlapping). These results indicated that interactions between nanotubes and polymer chains where taking place, bringing about a percolation network that suppressed reptation relaxation in flow, characterized by frequency-dependent moduli, $\mathrm{G}^{\prime} \sim \omega^{2}$ and $\mathrm{G}^{\prime \prime} \sim \omega$, with $\mathrm{G}^{\prime \prime}>\mathrm{G}$, at the terminal zone. Recently [19], the observation of a scaling of $\mathrm{G}^{\prime} \sim \omega^{0.5}$ at low frequencies was proposed as a criterion for the determination of the percolation threshold. In our case, an analysis of the data of Figure 1a at the light of the statistical percolation theory [13] was carried out, which allowed to evaluate the percolation threshold using the scaling law $\mathrm{G}^{\prime}=\mathrm{G}_{0}^{\prime}\left(\varphi-\varphi_{c}\right)^{t}$, where $\varphi_{c}$ is the percolation threshold and $t$ is an adjustable parameter. The rheological percolation threshold was evaluated considering the values of $\mathrm{G}^{\prime}$ taken at the lowest frequency $(0.0628 \mathrm{rad} / \mathrm{s})$ divided by the lowest value of the elastic modulus for neat $\mathrm{PP}, \mathrm{G}^{\prime}$ $(0.0628 \mathrm{rad} / \mathrm{s}) / \mathrm{G}_{0}$ value. The experimental data fitted to the scaling law of the percolation theory are presented in Figure 1b: The obtained percolation thresholds were $\varphi_{c}=1 \mathrm{wt} \%$ for the nanocomposites of Protocol A and $\varphi_{c}=0.3 \mathrm{wt} \%$ for the nanocomposites of Protocol B. This difference, found for two nanocomposites which were prepared using different methods is discussed below. 
Electrical conductivity results obtained at room temperature are displayed in Figure 2. Both nanocomposites showed electrical conductivities in the range of semiconductors for relatively low MWCNT concentrations, notwithstanding higher conductivities which were found for the nanocomposites prepared using protocol B. Actually, the electrical percolation threshold, which was determined using equation $\mathrm{X}=\mathrm{X}_{0}\left(\varphi-\varphi_{c}\right)^{t}$, taking $\mathrm{X}$ as the electrical conductivity at a frequency of $20 \mathrm{~Hz}$, was $\varphi_{c}=3.5 \mathrm{wt} \%$ for the nanocomposites of Protocol A and $\varphi_{c}=2 \mathrm{wt} \%$ for the nanocomposites of Protocol B. Therefore, in terms of industrial applications, mixing the nanocomposites after the PP matrix was irradiated (Protocol B) brought about more conductive nanocomposites than those obtained irradiating PP/MWCNT dispersions (Protocol A). This was certainly compatible with TEM results of Figure 3 which show a better MWCNT dispersion (smaller aggregates) for nanocomposites of Protocol B, as compared with Protocol A.

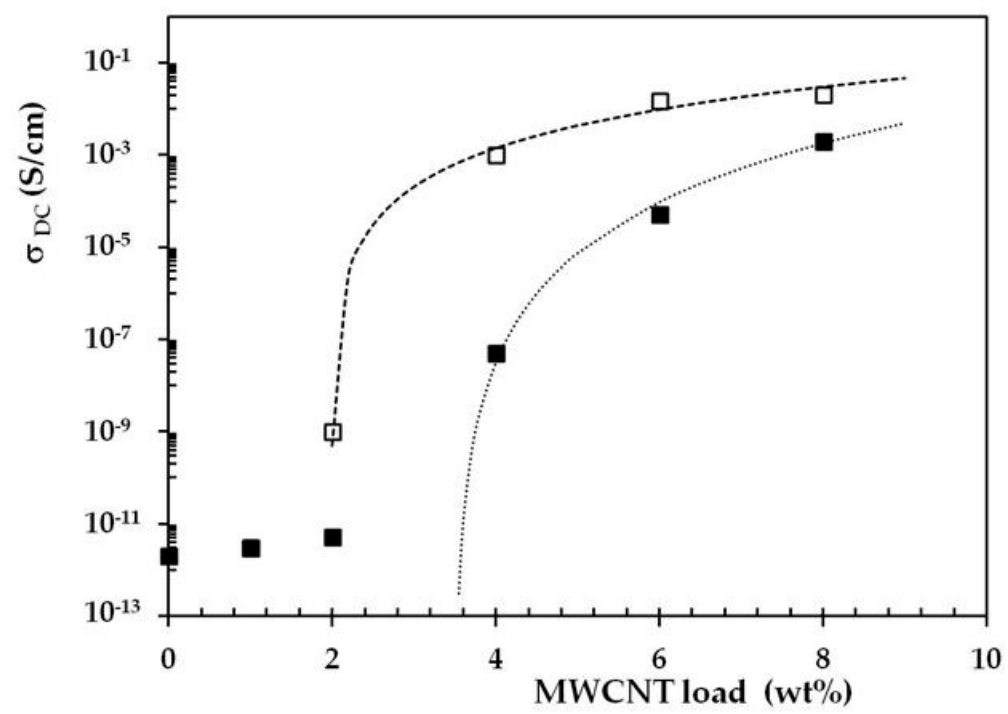

Figure 2. Electrical conductivity, $\sigma$, versus frequency for both nanocomposites elaborated using Protocol A (filled symbols) and Protocol B (empty symbols) respectively.

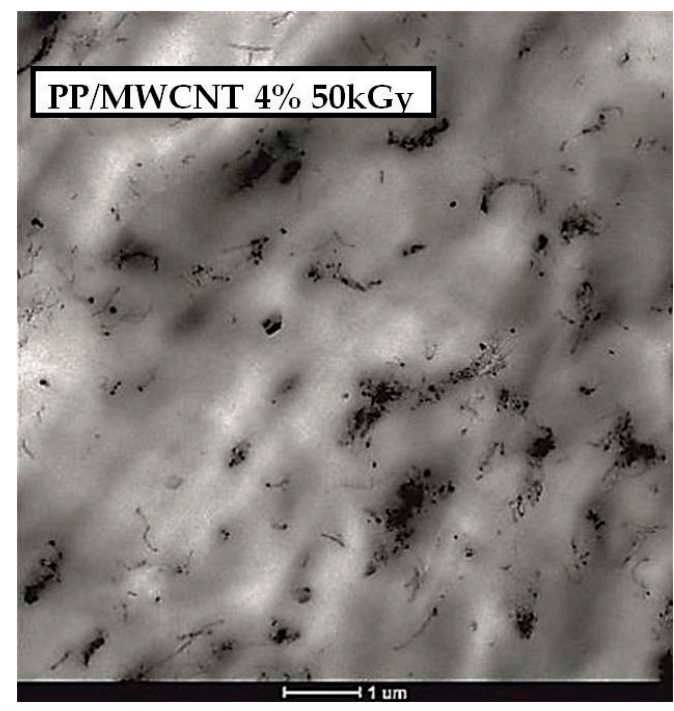

(a)

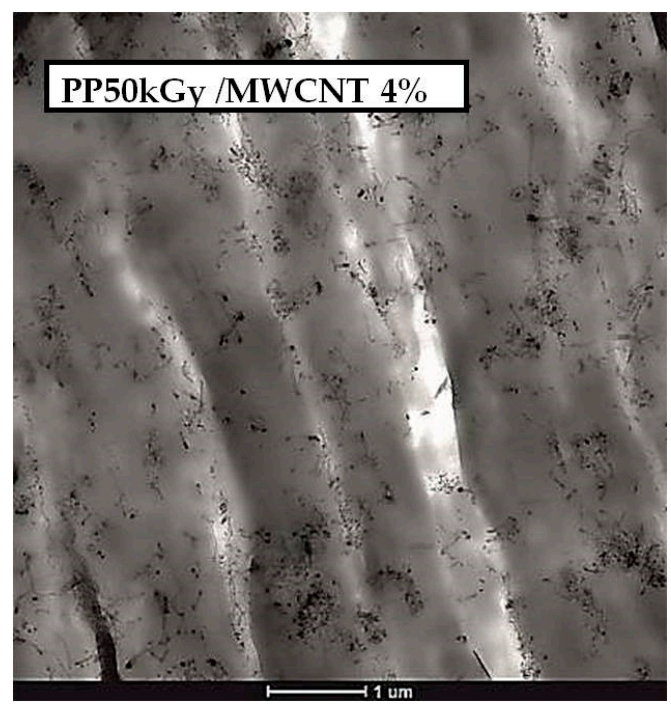

(b)

Figure 3. TEM microphotographs of $4 \%$ MWCNT nanocomposites. (a) Protocol A nanocomposite; (b) Protocol B nanocomposite. Better dispersion is observed for the nanocomposite obtained using Protocol B. 
It is well known [20-23] that the rheological behaviour of the matrix during mixing plays an important role in the degree of dispersion of the nanoparticles. In our case, the same mixing conditions (see Experimental Part) were employed to prepare the nanocomposites using both Protocol A and Protocol B. However, the molecular characteristics of the matrices were different, since in Protocol A non-irradiated PP was used, whereas in Protocol B an irradiated PP was employed. The most relevant effect of irradiation is the constitution of LCBs that give rise to a strain-hardening effect observed in elongational flow measurements. However, irradiation also produces typically a molecular weight reduction that leads to a viscosity decrease. Eventually, depending on the dose and temperature conditions, irradiations also leads to crosslinking, which was not the case in our work. Besides the SEC-GPC analysis, which is shown in the last part of the paper, the viscosity results presented in Figure 4 reveal the double effect of long chain branching and molecular weight decrease. Irradiated PP displayed a lower viscosity, which constitutes a symptom of molecular weight reduction, in addition to a shear thinning effect at low frequencies (instead of a Newtonian response, like in non-irradiated PP) characteristic of long chain branching $[2,5,24]$. The observed lower viscosity of irradiated PP stood for the better dispersion noticed by TEM (Figure 3) and, consequently, for the lower rheological percolation threshold value (Figure 1), as well as the lower electrical percolation threshold value (Figure 2) of the nanocomposites manufactured with Protocol B. A dispersion improvement is also observed for polymers subjected to a high intensity ultrasound in the work of Espinoza-González et al. [15].

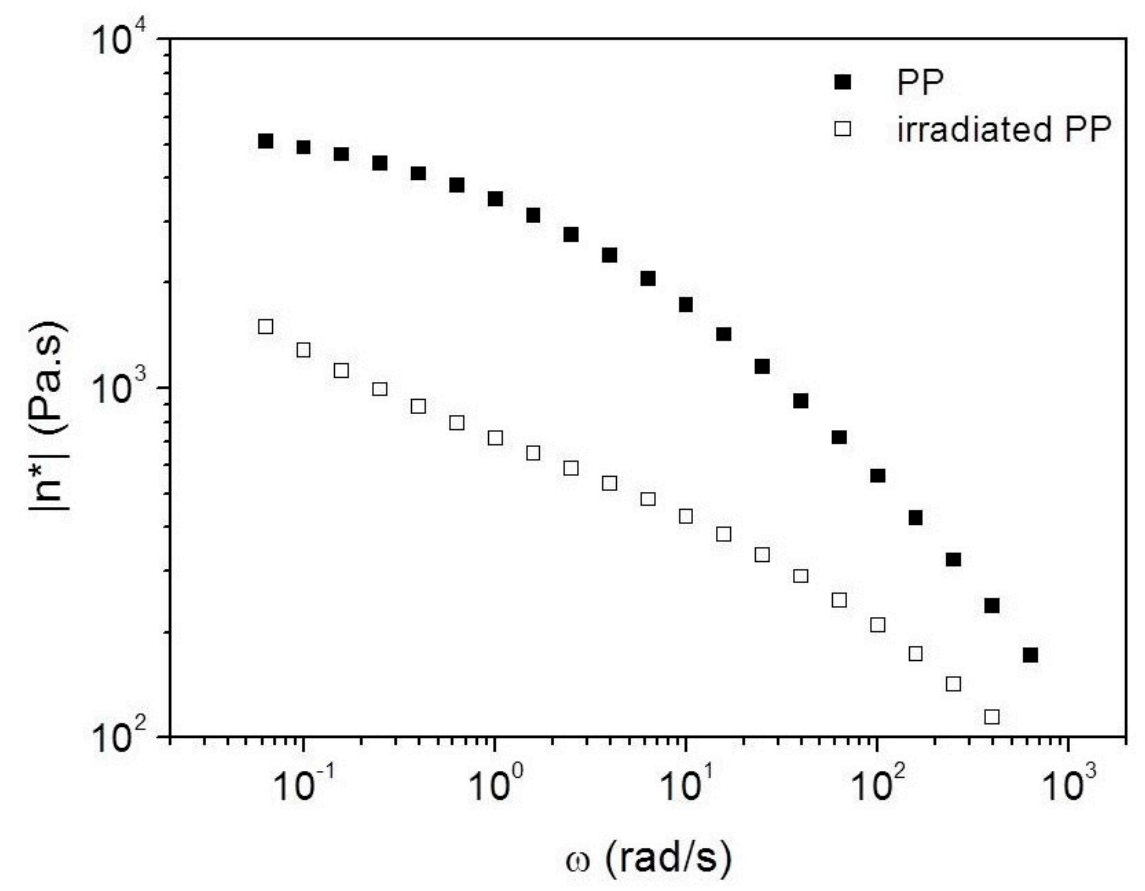

Figure 4. Comparison of the complex viscosity of pure PP before and after irradiation at $80 \mathrm{kGy}$. The irradiated sample shows shear thinning (concavity) behavior at low frequencies.

3.2. Elongational Flow and Large Amplitude Oscillatory Shear (LAOS) Flow: Differences between Both Types of Nanocomposites (Protocol A and Protocol B)

The results of linear elongational flow measurements of nanocomposites obtained respectively with Protocol A and Protocol B are displayed in Figure 5. The most remarkable outcome was the difference found at high times or elongational strains. Nanocomposites of Protocol A (Figure 5a) show a rapid increase of the elongational viscosity beyond a critical strain, which is referred to as strain hardening. Referring to polypropylene, this strain-hardening or dilatant behavior has been only reported for long chain branched samples obtained either by irradiation $[2,5,14,25,26]$ or by peroxydicarbonate modification $[27,28]$. However, in the case of nanocomposites manufactured using Protocol B (Figure 5b), no strain hardening was observed (strain softening was observed instead), 
suggesting that the polypropylene matrix was not long chain branched. This is an intriguing result, because Protocol B implies mixing the nanotubes with a PP which was submitted to irradiation and indeed produced strain-hardening behavior. This can be noticed in Figure 5b, which includes the data of the irradiated PP matrix. The cause of this apparent vanishing of LCB is explained in the last part of the paper.

Basically, the method used to analyse large amplitude oscillatory shear (LAOS) data in this work is the Fourier Transform analysis that decomposes stress data in a time domain into a frequency-dependent spectrum, with the first harmonic as the excitation frequency $\left(\omega_{1} / 2 \pi\right)$. For the case of a non-linear response, at large strain amplitudes the stress is no longer sinusoidal and further odd harmonics are obtained. The non-linearity can be quantified using the ratio $\mathrm{I}_{3} / \mathrm{I}_{1}=\mathrm{I}\left(\mathrm{n} \omega_{1}\right) / \mathrm{I}\left(\omega_{1}\right)$ with $\mathrm{I}_{\mathrm{n}}=\mathrm{I}\left(\mathrm{n} \omega_{1}\right)$ as the magnitude of the $\mathrm{n}$-th harmonic and $\mathrm{I}_{1}=\mathrm{I}\left(\omega_{1}\right)$ as the fundamental frequency. When the non-linear regime is reached, the third harmonic $\mathrm{I}_{3}$ rises above the noise level and $\mathrm{I}_{3} / \mathrm{I}_{1}$ shows a quadratic scaling relationship as a function of strain amplitude [18,29].

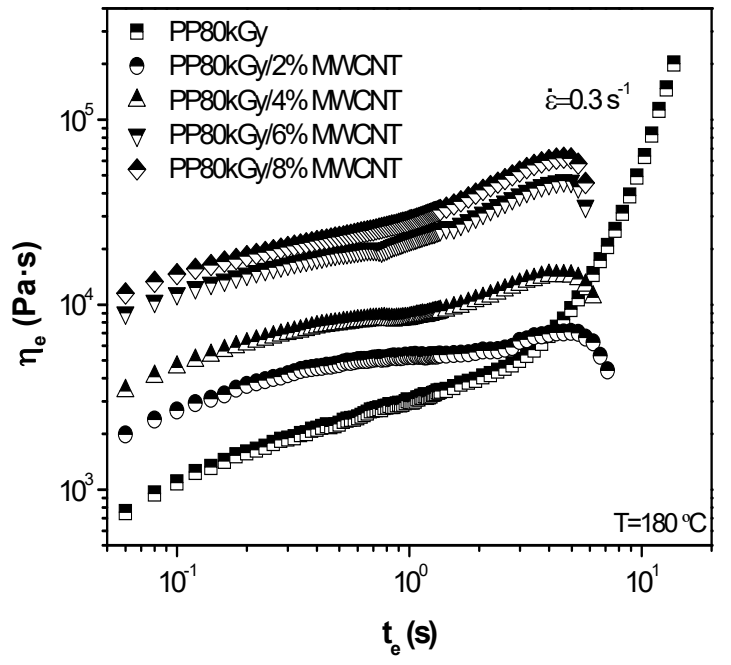

(a)

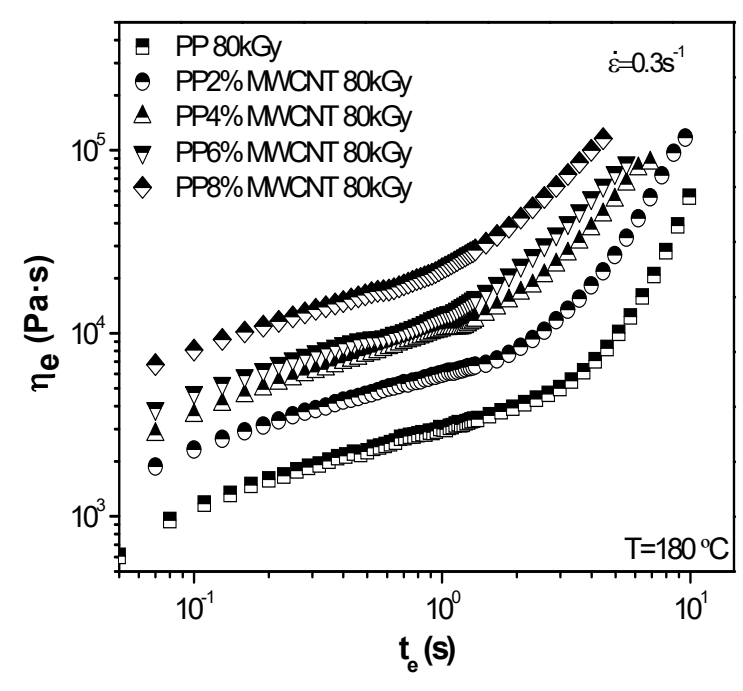

(b)

Figure 5. (a) Elongational viscosity vs. elongation time for the samples elaborated with Protocol A; (b) elongational viscosity vs. elongation time for the samples elaborated with Protocol B. Irradiated pure PP is also included for comparison purposes.

The capacity of LAOS to detect and evaluate long chain branching in irradiated MWCNT/PP nanocomposites was described in a paper of our group [12], where the effect of irradiation on LAOS results of pure PP and PP/MWCNT nanocomposites (equivalent to Protocol A of this paper) was investigated. SEC-GPC results came to demonstrate that irradiation caused long chain branching and LAOS data were correlated to the degree of LCB. An increase of the intensity of the third harmonic relative to the intensity of the response at the fundamental frequency, $\mathrm{I}_{3} / \mathrm{I}_{1}$, was observed, as $\mathrm{LCB}$ level increased, with respect to linear nonirradiated samples. The LAOS results of our nanocomposites (Protocol A and Protocol B) are presented in Figure $6 . \mathrm{I}_{3} / \mathrm{I}_{1}$ values at large amplitudes were higher for irradiated PP and Protocol A, than those of nonirradiated PP. A decrease of the intensity of the third harmonic at the higher strains is observed for the Protocol B nanocomposite. Concomitantly with elongational flow results, two groups of materials could be established: On the one hand, irradiated PP and nanocomposites of Protocol A which showed strain-hardening and relatively high values of $\mathrm{I}_{3} / \mathrm{I}_{1}$, and on the other hand, non-irradiated PP and nanocomposites of Protocol B which did not display any of these rheological features. The results of nanocomposites of Protocol B, which behave like a linear PP in both elongational flow and LAOS experiments, seemed to indicate that LCB disappeared during the extrusion accomplished to prepare the nanocomposite. 


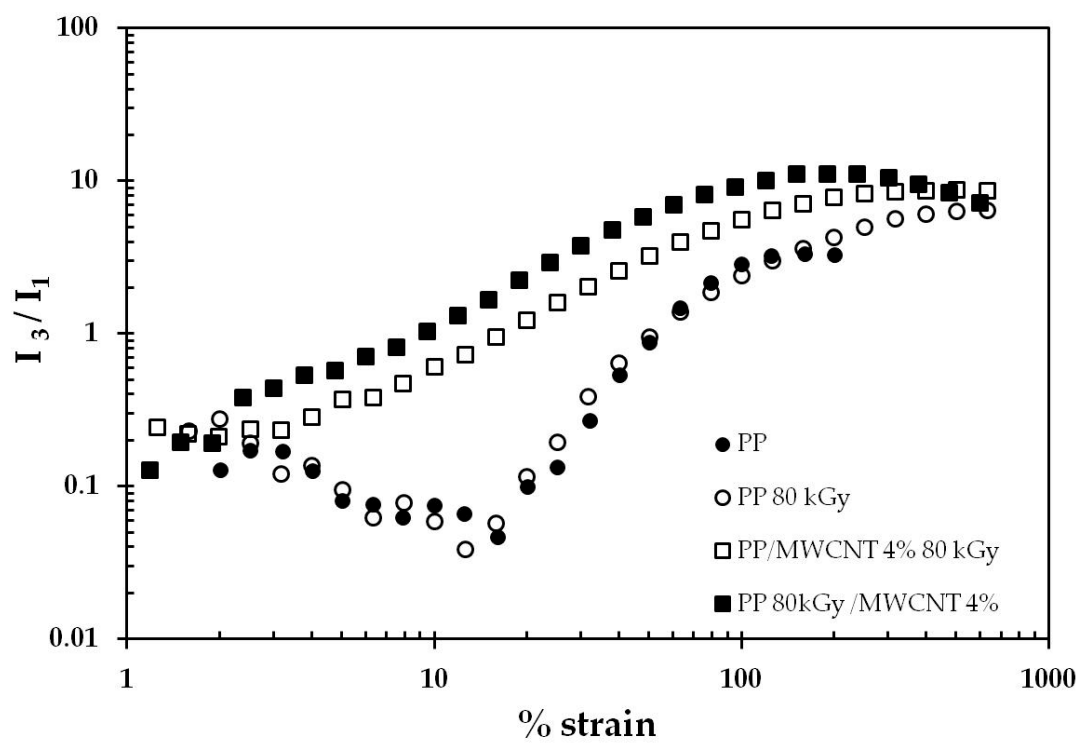

Figure 6. LAOS results (see text) for PP, irradiated PP (PP $80 \mathrm{kGy}$ ), Protocol A nanocomposite (PP/MWCNT 4\% $80 \mathrm{kGy}$ ) and Protocol B nanocomposite (PP 80 kGy/MWCNT 4\%). The values of $\mathrm{I}_{3} / \mathrm{I}_{1}$ at large amplitudes are higher for irradiated PP and nanocomposites of Protocol $\mathrm{A}$, with respect to PP and Protocol B.

\subsection{Shear Modification and Recovery: Alignment and Misalignment}

An analysis of the PP matrix was required to investigate the molecular changes suffered by the irradiated PP during the extrusion carried out for mixing with MWCNTs to prepare the nanocomposites of Protocol B. A GPC-SEC analysis of the irradiated PP matrix before and after submitting it to mixing is shown in Figure 7. For comparison purposes, the results of PP irradiated at different irradiation doses are also presented in this figure and in Table 1. Long chain branches were detected in irradiated PP submitted to processing, although the level was considerably lower than that of the non-processed sample. As an exception, the LCB level of the PP irradiated at $80 \mathrm{kGy}$ and submitted to extrusion was higher than that of the PP irradiated at $20 \mathrm{kGy}$ (the lower irradiation dose) but not submitted to extrusion. Interestingly enough, the latter brought about strain-hardening behavior (not shown here), which was significant, because its LCB level was lower than that of the extruded PP (Figure 7 and Table 1). In consequence, although a considerable decrease of LCB level was observed in the extruded PP, this was not responsible for the complete vanishing of strain-hardening observed in Figure 5. Instead, the phenomenon of strain-hardening disappearance could be ascribed to the conformation change of the branched structure, as alignment of long branches to the backbone chains during processing took place. The aligned branches passed to behave like linear chains and, therefore, strain hardening was not observed. This reasoning is based on the concept of shear modification phenomenon, according to which the existence of long chain branches leads to rheological changes by processing involving straining and thermal history [30-32].

Table 1. Molecular parameters including LCB density evaluated using SEC Chromatography coupled with three detectors of non-irradiated, irradiated PP and processed irradiated PP.

\begin{tabular}{cccccc}
\hline Molecular Parameters & PP & PP 20 kGy & PP50 kGy & PP80 kGy & PP80 Kg (Processed) \\
\hline Mw (g/mol) & 298,000 & 287,000 & 237,000 & 168,000 & 191,060 \\
Mn (g/mol) & 33,000 & 41,000 & 40,000 & 34,000 & 26,339 \\
Mz (g/mol) & 755,000 & $1,350,000$ & $1,360,000$ & 900,000 & 706,371 \\
Mw/Mn & 9 & 7 & 6 & 5 & 7.4 \\
LCBf/1000C & - & 0.011 & 0.03 & 0.036 & 0.023 \\
\hline
\end{tabular}




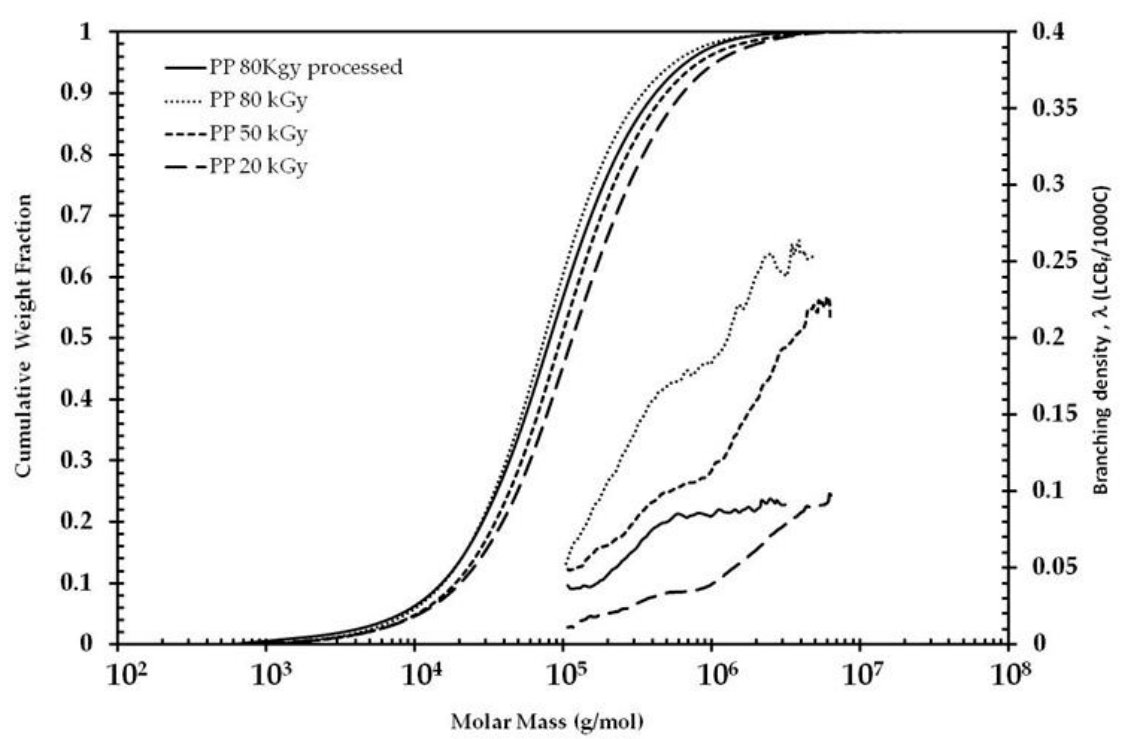

Figure 7. Branching density $\lambda(\mathrm{LCB} / 1000 \mathrm{C})$ and cumulative molar mass distribution for irradiated PP samples obtained by triple detection GPC-SEC.

To confirm this hypothesis, an analysis of the eventual recovery of the original conformation, when the sample was submitted to temperatures $\mathrm{T}>\mathrm{Tm}$ in the quiescent state, had to be done. The elongational flow data of the extruded PP sample that was annealed at $\mathrm{T}=160{ }^{\circ} \mathrm{C}$ during $8 \mathrm{~h}$ in a vacuum oven (presented in Figure 8) suggests the recovery of the conformation. This was manifested in the strain hardening shown by the annealed sample, which is in contrast to the sample not submitted to thermal treatment.

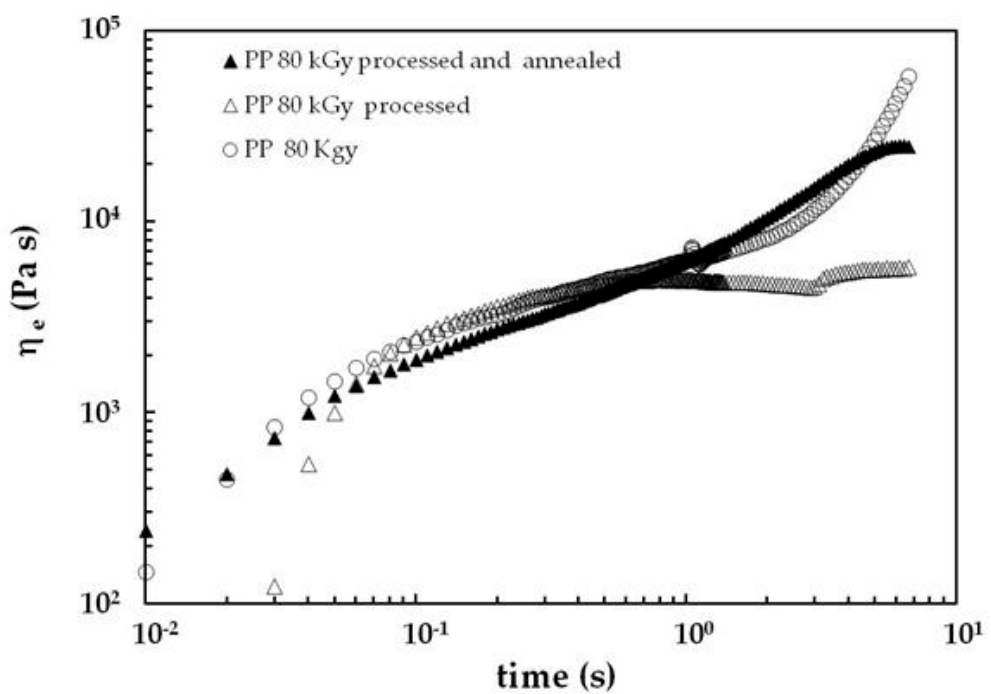

Figure 8. Uniaxial viscosity as a function of time obtained at $\mathrm{T}=180{ }^{\circ} \mathrm{C}$ at $0.3 \mathrm{~s}^{-1}$ elongational rate. PP80 KGy is the Irradiated PP distinguished by the strain-hardening behaviour. PP80 kGy processed is the extruded irradiated PP distinguished by the absence of strain hardening. PP80 kGy processed and annealed shows the strain hardening behavior, which has been recovered during the annealing process at $\mathrm{T}=160^{\circ} \mathrm{C}$ in a vacuum oven during $8 \mathrm{~h}$.

Considering this result, the question of an eventual repercussion of the recovery on LAOS results was posed. LAOS results of Figure 6 show a relative reduction of the value of $I_{3} / I_{1}$ at large deformations for nanocomposites of Protocol B with respect to Protocol A, denoting the effect of the extrusion process. At this point we wondered if a recovery of $\mathrm{I}_{3} / \mathrm{I}_{1}$ was possible, in parallel to the observed strain-hardening recovery. The positive answer to this question is given in Figure 9, which 
shows that annealing during $8 \mathrm{~h}$ at $160^{\circ} \mathrm{C}$ in the extruded irradiated PP led to $\mathrm{I}_{3} / \mathrm{I}_{1}$ values close to those of non-extruded irradiated PP. The recovery similitude observed in two different experiments (elongational flow and LAOS) leads us to assume that annealing was able to produce a misalignment or return to the original chain conformation of the aligned long chain branches. Certainly, during extrusion for the preparation of nanocomposites by Protocol B, the LCB level of PP was reduced (as can be seen in Figure 7), but this reduction did not justify the strain hardening vanishing, because PP with a lower amount of LCB was able to bring about strain hardening. This leads us to conclude that although during processing two effects were produced, reduction of LCB level (irreversible) and chain alignment (reversible), only the last one was responsible for the elimination of strain hardening and the significant reduction of the value of $\mathrm{I}_{3} / \mathrm{I}_{1}$ at high deformations. The reversibility of the chain alignment process was confirmed by the results achieved with the PP submitted to extrusion in conditions similar to mixing and annealed during $8 \mathrm{~h}$ at $\mathrm{T}=160^{\circ} \mathrm{C}$. Obviously, the thermal treatment could not be able to recover the eliminated $\mathrm{LCB}$, but was capable of misaligning the chains leading them to the conformation previous to processing.

The analysis of the recovery was also carried out on the nanocomposites obtained with the irradiated matrix. Samples were annealed at $\mathrm{T}=160^{\circ} \mathrm{C}$ during $8 \mathrm{~h}$ in vacuum, but no recovery was observed. The viscoelastic response of the nanocomposites was clearly dependent on the MWCNT content. The conformational structure previous to processing could not be recovered because the viscous flow region was delayed to very long times, which prevented the misaligning capability of the long chains at the annealing conditions.

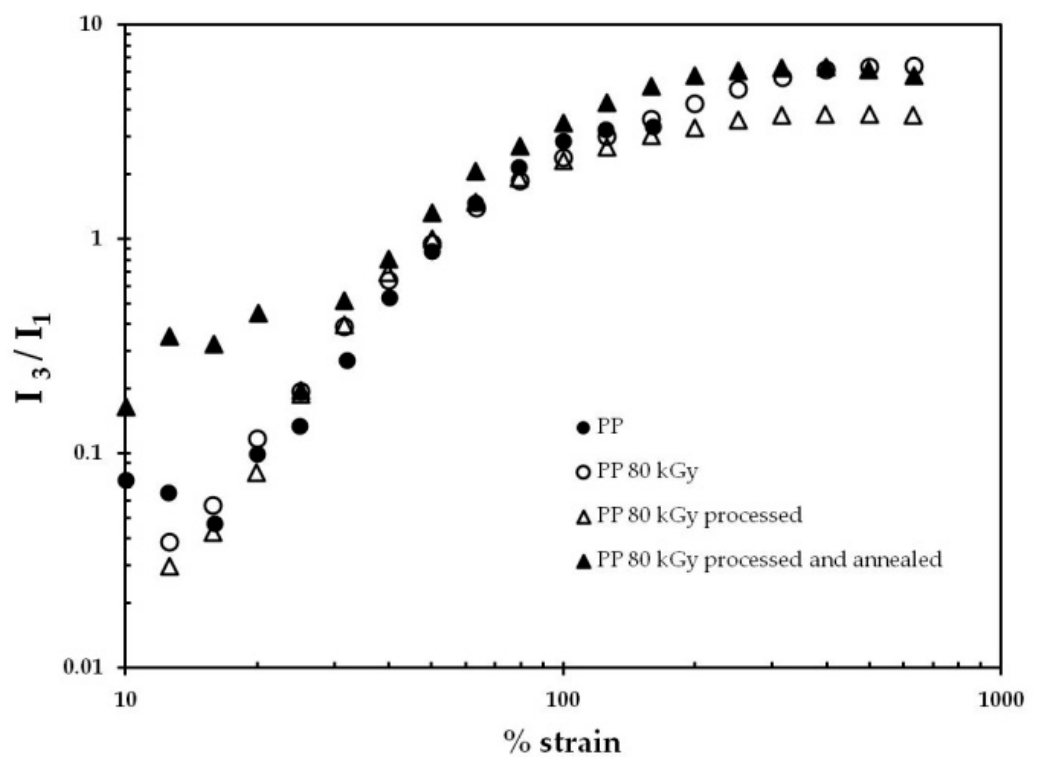

Figure 9. LAOS results (see text) for PP, irradiated PP, irradiated PP processed and irradiated PP processed and annealed during $8 \mathrm{~h}$ at $\mathrm{T}=160^{\circ} \mathrm{C}$ in vacuum.

\section{Conclusions}

Two protocols both involving an irradiation process were employed to prepare PP/MWCNT nanocomposites. Protocol A was achieved mixing first PP and MWCNTs in an extruder and then irradiating the obtained dispersion, and Protocol B was carried out irradiating first PP and then mixing it after with MWCNTs in an extruder. As noticed by TEM, Protocol B led to a better dispersion, bringing about lower rheological and electrical percolation thresholds. The reason for this outcome was the lower viscosity found in the irradiated PP matrix involved in Protocol B, which in turn was due to a molecular weight reduction.

Elongational flow results were striking at first sight. Strain hardening in elongational flow measurements, typical of irradiated PPs, was observed for the nanocomposite of Protocol A, but not for 
the nanocomposite of Protocol B. The practical consequences of this result were relevant, because strain hardening is a necessary condition to achieve certain industrial processes, such as extrusion-blowing, blow molding, foaming extrusion and thermoforming.

Moreover, LAOS results showed large $\mathrm{I}_{3} / \mathrm{I}_{1}$ values for irradiated PP and the nanocomposite of Protocol A, as compared with non-irradiated PP and the nanocomposite of Protocol B. Since it is accepted that strain hardening observed in irradiated PPs owes to LCB, and, on the other hand, larger $\mathrm{I}_{3} / \mathrm{I}_{1}$ values for long chain branched PPs have been reported, the initial conclusion was that no LCB was in the matrix of the nanocomposite of Protocol B. However, SEC GPC analysis of a polypropylene sample submitted to the same irradiation and mixing conditions as that carried out in Protocol B, revealed a level of LCB that should have been enough to provoke strain hardening. The hypothesis of a shear modification that aligned the branches into the backbone, eliminating the strain hardening, was considered. Recovery of the strain hardening and $\mathrm{I}_{3} / \mathrm{I}_{1}$ values by annealing the sample at $\mathrm{T}=160^{\circ} \mathrm{C}$ during $8 \mathrm{~h}$ to promote a misalignment of the branches, led us to demonstrate that although an irreversible destruction of LCBs was taking place during mixing, the actual reason for the observed rheological changes was shear modification.

Author Contributions: Conceptualization, A.S., A.H., and M.F.; Methodology, A.H., and M.F.; Software, A.H. and M.F.; Formal Analysis, A.S., A.H., and M.F.; Investigation, A.S., A.H., and M.F.; Data Curation, A.H. and M.F.; Writing-Original Draft Preparation, A.S.; Writing — Review \& Editing, A.S. and M.F.; Supervision, A.S.; Project Administration, A.S.; Funding Acquisition, A.S., and A.H.

Funding: This research received no external funding.

Acknowledgments: The authors are grateful to the financial support from the Basque Government (GIC IT-586-13). A. Huegun would like to thank to the Spanish Government for the grant BES-2008-002469.

Conflicts of Interest: The authors declare no conflict of interest.

\section{References}

1. Rätzsch, M. Special PP's for a developing and future market. J. Macromol. Sci. Pure Appl. Chem. 1999, 36, 1587-1611. [CrossRef]

2. Pötschke, P.; Krause, B.; Stange, J.; Münstedt, H. Elongational viscosity and foaming behavior of PP modified by electron irradiation or nanotube addition. Macromol. Symp. 2007, 254, 400-408. [CrossRef]

3. Auhl, D.; Stadler, F.J.; Münstedt, H. Comparison of molecular structure and rheological properties of electron-beam- and gamma-irradiated polypropylene. Macromolecules 2012, 45, 2057-2065. [CrossRef]

4. Mishra, R.; Tripathy, S.P.; Dwivedi, K.K.; Khathing, D.T.; Ghosh, S.; Müller, M.; Fink, D. Electron induced modification in polypropylene. Radiat. Meas. 2001, 33, 845-850. [CrossRef]

5. Auhl, D.; Stange, J.; Münstedt, H.; Krause, B.; Voigt, D.; Lederer, A.; Lappan, U.; Lunkwitz, K. Long-chain branched polypropylenes by electron beam irradiation and their rheological properties. Macromolecules 2004, 37, 9465-9472. [CrossRef]

6. Krause, B.; Stephan, M.; Volkland, S.; Voigt, D.; Häußler, L.; Dorschner, H. Long-chain branching of polypropylene by electron-beam irradiation in the molten state. J. Appl. Polym. Sci. 2006, 99, 260-265. [CrossRef]

7. Nakamura, S.; Tokumitsu, K. Influence of electron beam irradiation on mechanical and thermal properties of polypropylene/polyamide blend. AIP Conf. Proc. 2014, 1593, 666-669. [CrossRef]

8. Hassan, F.; Entezam, M. Electron Beam Irradiation Method to Change Polypropylene Application: Rheology and Thermo-Mechanical Properties. Polyolefins J. 2018, 6, 53-61. [CrossRef]

9. Bee, S.T.; Sin, L.T.; Hoe, T.T.; Ratnam, C.T.; Bee, S.L.; Rahmat, A.R. Study of montmorillonite nanoparticles and electron beam irradiation interaction of ethylene vinyl acetate (EVA)/de-vulcanized waste rubber thermoplastic composites. Nucl. Instrum. Methods Phys. Res. Sect. B 2018, 423, 97-110. [CrossRef]

10. Lotfy, S.; Atta, A.; Abdeltwab, E. Comparative study of gamma and ion beam irradiation of polymeric nanocomposite on electrical conductivity. J. Appl. Polym. Sci. 2018, 135, 1-7. [CrossRef]

11. Martínez-Morlanes, M.J.; Castell, P.; Martínez-Nogués, V.; Martinez, M.T.; Alonso, P.J.; Puértolas, J.A. Effects of gamma-irradiation on UHMWPE/MWNT nanocomposites. Compos. Sci. Technol. 2011, 71, 282-288. [CrossRef] 
12. Fernandez, M.; Huegun, A.; Muñoz, M.E.; Santamaria, A. Nonlinear oscillatory shear flow as a tool to characterize irradiated polypropylene/MWCNT nanocomposites. Appl. Rheol. 2015, 25, 1-12. [CrossRef]

13. Noll, A.; Burkhart, T. Morphological characterization and modelling of electrical conductivity of multi-walled carbon nanotube/poly(p-phenylene sulfide) nanocomposites obtained by twin screw extrusion. Compos. Sci. Technol. 2011, 71, 499-505. [CrossRef]

14. Huegun, A.; Fernández, M.; Muñoz, M.E.; Santamaría, A. Rheological properties and electrical conductivity of irradiated MWCNT/PP nanocomposites. Compos. Sci. Technol. 2012. [CrossRef]

15. Espinoza-Gonzalez, C.; Avila-Orta, C.; Martinez-Colunga, G.; Lionetto, F.; Maffezzoli, A. A measure of CNTs dispersion in polymers with branched molecular architectures by UDMA. IEEE Trans. Nanotechnol. 2016, 15, 731-737. [CrossRef]

16. Vega, J.F.; da Silva, Y.; Vicente-Alique, V.; Núñez-Ramírez, R.; Trujillo, M.; Arnal, M.L.; Müller, A.J.; Dubois, P.; Martínez-Salazar, J. Influence of chain branching and molecular weight on melt rheology and crystallization of polyehtylene/carbon nanotube nanocomposites. Macromolecules 2014, 47, 5668-5681. [CrossRef]

17. Cangussú, M.E.; de Azeredo, A.P.; Simanke, A.G.; Monrabal, B. Characterizing Long Chain Branching in Polypropylene. Macromol. Symp. 2018, 377, 1-9. [CrossRef]

18. Wilhelm, M. Fourier-transform rheology. Macromol. Mater. Eng. 2002, 287, 83-105. [CrossRef]

19. Hassanabadi, H.M.; Wilhelm, M.; Rodrigue, D. A rheological criterion to determine the percolation threshold in polymer nano-composites. Rheol. Acta 2014, 53, 869-882. [CrossRef]

20. McNally, T.; Potschke, P. Polymer-Carbon Nanotube Composites: Preparation, properties and Applications; Elsevier: New York, NY, USA, 2011.

21. Alig, I.; Pötschke, P.; Lellinger, D.; Skipa, T.; Pegel, S.; Kasaliwal, G.R.; Villmow, T. Establishment, morphology and properties of carbon nanotube networks in polymer melts. Polymer 2012, 53, 4-28. [CrossRef]

22. Du, F.; Scogna, R.C.; Zhou, W.; Brand, S.; Fischer, J.E.; Winey, K.I. Nanotube networks in polymer nanocomposites: Rheology and electrical conductivity. Macromolecules 2004, 37, 9048-9055. [CrossRef]

23. Kasaliwal, G.R.; Göldel, A.; Pötschke, P.; Heinrich, G. Influences of polymer matrix melt viscosity and molecular weight on MWCNT agglomerate dispersion. Polymer 2011, 52, 1027-1036. [CrossRef]

24. Rojo, E.; Muñoz, M.E.; Mateos, A.; Santamaría, A. Flow instabilities in linear and branched syndiotactic poly(propylene)s. Macromol. Mater. Eng. 2007, 292, 1210-1217. [CrossRef]

25. Schulze, D.; Mu, R. Rheological evidence of modifications of polypropylene by b-irradiation. Rheol. Acta 2003, 251-258. [CrossRef]

26. Sugimoto, M.; Tanaka, T.; Masubuchi, Y.; Takimoto, J.I.; Koyama, K. Effect of chain structure on the melt rheology of modified polypropylene. J. Appl. Polym. Sci. 1999, 73, 1493-1500. [CrossRef]

27. Lagendijk, R.P.; Hogt, A.H.; Buijtenhuijs, A.; Gotsis, A.D. Peroxydicarbonate modification of polypropylene and extensional flow properties. Polymer 2001, 42, 10035-10043. [CrossRef]

28. Gotsis, A.D.; Zeevenhoven, B.L.F.; Hogt, A.H. The effect of long chain branching on the processability of polypropylene in thermoforming. Polym. Eng. Sci. 2004, 44, 973-982. [CrossRef]

29. Hyun, K.; Wilhelm, M.; Klein, C.O.; Cho, K.S.; Nam, J.G.; Ahn, K.H.; Lee, S.J.; Ewoldt, R.H.; McKinley, G.H. A review of nonlinear oscillatory shear tests: Analysis and application of large amplitude oscillatory shear (LAOS). Prog. Polym. Sci. 2011, 36, 1697-1753. [CrossRef]

30. Münstedt, $H$. The influence of various deformation histories on elongational properties of low density polyethylene. Colloid Polym. Sci. 1981, 259, 966-972. [CrossRef]

31. Yamaguchi, M.; Wagner, M.H. Impact of processing history on rheological properties for branched polypropylene. Polymer 2006, 47, 3629-3635. [CrossRef]

32. Luo, Y.; Xin, C.; Zheng, D.; Li, Z.; Zhu, W.; Wu, S.; Zheng, Q.; He, Y. Effect of processing history on the rheological properties, crystallization and foamability of branched polypropylene. J. Polym. Res. 2015, 22, 1-13. [CrossRef]

(C) 2019 by the authors. Licensee MDPI, Basel, Switzerland. This article is an open access article distributed under the terms and conditions of the Creative Commons Attribution (CC BY) license (http:/ / creativecommons.org/licenses/by/4.0/). 